\title{
Traducción audiovisual accesible a personas con discapacidad intelectual mediante el uso de subtítulos adaptados
}

\author{
Teresa Alba RodríGuez \\ Universidad de Málaga \\ teresalbarguez@gmail.com
}

Recibido: 15 de diciembre de 2013

Aceptado: 14 de febrero de 2014

\section{RESUMEN}

Este artículo pretende dar cuenta de la situación actual en accesibilidad multimedia a personas con discapacidad intelectual que, hoy por hoy, necesitan la ayuda de otros en numerosas ocasiones para entender la información presente en mensajes audiovisuales como es el caso de películas, series de televisión, documentales, noticias, páginas web, etc. Pretendo demostrar que los traductores podemos servir de puente entre este contenido y quienes presentan este tipo de discapacidad mediante el uso de lo que sería una nueva modalidad, a la que podríamos denominar "subtitulación adaptada para personas con discapacidad intelectual".

Palabras clave: traducción audiovisual, subtitulación, accesibilidad, discapacidad intelectual.

Audiovisual translation for people with intellectual disability by using adapted subtitles

\begin{abstract}
This article tries to explain the current situation in multimedia accessibility to people with intellectual disability that often need to be helped by others in order to understand the information which appears in audiovisual messages like films, TV series, documentaries, news, webpages, etc. I attempt to demonstrate that translators can serve as a bridge towards this content and who present this disability by using a new modality, which we could call "subtitling adapted to people with intellectual disability".
\end{abstract}

Keywords: audiovisual translation, subtitling, accessibility, intellectual disability.

Sumario: 1. Traducción audiovisual y accesibilidad. 2. Panorama actual en accesibilidad a personas con discapacidad intelectual. 3. ¿Qué es la discapacidad intelectual? 4. Pasos previos a la elaboración de los subtítulos adaptados. 5. Pautas de la propuesta. 6. Conclusiones. 


\section{Traducción audiovisual y accesibilidad}

A pesar de que el origen de la traducción audiovisual (TAV) se remonta a más de dos siglos con los inicios del cine, Díaz Cintas (2007: 9) señala el auge de esta disciplina en los años noventa debido a los congresos y jornadas llevados a cabo, así como a la creación de asociaciones, publicaciones, tesis doctorales, asignaturas académicas y cursos impartidos. Para delimitar el concepto de TAV me gustaría aludir a las siguientes palabras de Orero (2004: 8) "Audiovisual Translation will encompass all translations -or multisemiotic transfer-for production or postproduction in any media or format, and also the new areas of media accessibility: subtitling for the deaf and the hard of hearing and audiodescription for the blind and the visually impaired".

Desde sus inicios hasta nuestros días se han ido configurando diferentes modalidades dentro de este ámbito, entre ellas las que Orero señala como "the new areas of media accessibility", que precisamente son las que me han proporcionado la idea de llevar a cabo una propuesta de traducción que ayude a las personas con discapacidad intelectual a comprender los mensajes multimedia que les rodean. Estas modalidades en español se conocen como el "subtitulado para personas sordas y personas con discapacidad auditiva" (SPS) y la "audiodescripción para personas ciegas y deficientes visuales" (AD). El SPS es:

Una práctica socio-lingüística que consiste en ofrecer, generalmente en la parte inferior de la pantalla, aunque no siempre, un texto escrito que pretende dar cuenta de los diálogos y la identidad de los actores o personas que hablan en el programa audiovisual; la información suprasegmental que acompaña la entrega de ciertos diálogos o monólogos: entonación, acentos, ritmo, prosodia, etc.; los efectos sonoros que se escuchan en la pista sonora; aquellos elementos discursivos que forman parte de la fotografía y están en otros idiomas: cartas, pintadas, leyendas, pantallas de ordenador, pancartas, etc.; otros elementos discursivos transmitidos a través de la pista sonora, como las canciones y la música (Díaz Cintas 2007: 14-15).

Por otro lado, la norma UNE 153 020, “Audiodescripción para personas con discapacidad visual" (AENOR 2005), define esta práctica como sigue:

La audiodescripción es el servicio de apoyo a la comunicación que consiste en el conjunto de técnicas y habilidades aplicadas, con objeto de compensar la carencia de captación de la parte visual contenida en cualquier tipo de mensaje, suministrando una adecuada información sonora que la traduce o explica, de manera que el posible receptor discapacitado visual perciba dicho mensaje como un todo armónico y de la forma más parecida a como lo percibe una persona que ve (Jiménez 2007: 57).

No obstante, el punto de partida real de esta propuesta de accesibilidad cognitiva es la subtitulación que, en palabras de Díaz Cintas (2003: 32), se define como la "práctica lingüística que consiste en ofrecer, generalmente en la parte inferior de la pantalla, un texto escrito que pretende dar cuenta de los diálogos de los actores, así como 
de aquellos elementos discursivos que forman parte de la fotografia (cartas, pintadas, leyendas, pancartas, etc.) o de la pista sonora (canciones, voces en off, etc.)".

Asimismo, me gustaría comentar que esta investigación encuentra su origen en la elaboración de mi trabajo de fin de grado en el que tras estudiar las distintas prácticas que conciernen a la TAV y con un especial interés por las modalidades accesibles para personas con discapacidad sensorial me planteaba el siguiente interrogante: ¿por qué no servirnos de estos precedentes para conseguir una práctica accesible destinada a personas con discapacidad intelectual? Podemos observar antecedentes de accesibilidad dentro de esta disciplina. Como argumento me gustaría añadir a las prácticas accesibles anteriormente nombradas la existencia de otras modalidades, que aun siendo menos conocidas, permiten acercar los mensajes multimedia a personas con discapacidad sensorial: este es el caso de la interpretación del lenguaje de signos (ILS), "A language that uses a system of manual, facial, and other body movements as the means of communication. It has to be noted that there is no widely accepted international sign language. Many national versions exist together with local dialects" (Miller 2007: 54); la interpretación simultánea/bilateral con apoyo táctil (Quereda Herrera 2007: 229-240), que ha sido llevada a cabo de modo experimental en clases de anatomía de la Universidad de Granada, en la que los intérpretes se sirven de apoyo material que puede ser un objeto o incluso el propio cuerpo; la audiodescripción susurrada o chuchotage audiodescriptivo, investigada también en la Universidad de Granada y sobre la que Márquez (2007: 209227) afirma que a efectos prácticos es lo mismo que se realiza en la audiodescripción susurrada: "Interpretación in situ realizada en voz baja y destinada a una audiencia muy reducida" con la peculiaridad de que no se interpreta un texto origen sino imágenes; así como la comunicación con personas con sordoceguera mediante los sistemas de comunicación alfabéticos y los no alfabéticos, que, a mi juicio, creo que pueden ser considerados una modalidad más de interpretación accesible dentro del ámbito de la transmisión de mensajes multimedia a personas con discapacidad sensorial (ASOCIDE: en línea).

En mi opinión, no solo por todos los antecedentes que podemos observar en el ámbito de la accesibilidad en TAV, sino por ley, pienso que estamos obligados a llevar a cabo esta práctica o cualquier otra con función similar de manera que se cubran las necesidades de este colectivo. Así lo recoge la "Ley 26/2011, de 1 de agosto, de adaptación normativa a la Convención Internacional sobre los Derechos de las Personas con Discapacidad" (BOE 2011: 87 478-87 494), que modifica a la Ley $51 / 2003$, de 2 de diciembre, de igualdad de oportunidades, no discriminación y accesibilidad universal de las personas con discapacidad (BOE 2003: 43 187-43 195), en el apartado 1 del artículo 1: "Asimismo, se entiende por igualdad de oportunidades la adopción de medidas de acción positiva orientadas a evitar o compensar las desventajas de una persona con discapacidad para participar plenamente en la vida política, económica, cultural y social” (BOE 2011: 87 480).

\section{Panorama actual en accesibilidad a personas con discapacidad intelectual}

En la actualidad, podemos encontrar diversos métodos que contribuyen a la accesibilidad a contenidos multimedia para las personas con discapacidad sensorial 
mediante la traducción intralingüística y el uso de ayudas técnicas y herramientas de rehabilitación, hecho que hace incomprensible el deficiente desarrollo de material que estudie y posibilite la práctica accesible de contenido multimedia a personas con discapacidad intelectual.

En mi opinión, para que todos consigamos tener el mismo derecho de participación e inclusión plena y efectiva en la sociedad todo material multimedia tiene que ser de fácil acceso sin barreras tecnológicas o lingüísticas. Así se supone en el artículo 21 de la Convención de las Naciones Unidas sobre los derechos de las personas con discapacidad, libertad de expresión y de opinión y acceso a la información (ONU: en línea), del cual me gustaría subrayar el siguiente apartado: "Facilitar a las personas con discapacidad información dirigida al público en general, de manera oportuna y sin costo adicional, en formatos accesibles y con las tecnologías adecuadas a los diferentes tipos de discapacidad" (ONU 2006: 16).

Antes de continuar, quisiera comentar que existen algunas asociaciones que en la actualidad trabajan la accesibilidad multimedia destinada a personas con discapacidad intelectual; este es el caso de CENTAC (Centro Nacional de Tecnologías de la Accesibilidad) que organizó en el año 2012 un taller de expertos sobre accesibilidad cognitiva, donde se hizo visible la necesidad de una normativa legal española en materia de inclusión para acercar las TIC a quienes presentan cualquier tipo de discapacidad (CENTAC: en línea).

Del mismo modo, existen organizaciones y entidades que colaboran para que las noticias, libros y documentos, mediante la denominada "lectura fácil", sean accesibles. Discapnet, el Portal de las personas con discapacidad, es una de ellas y define esta práctica como sigue: "Aquellos contenidos que han sido resumidos y realizados con lenguaje sencillo y claro, de forma que puedan ser entendidos por personas con discapacidad cognitiva o discapacidad intelectual" (Discapnet: en línea). Además, Discapnet informa acerca de la existencia de varios niveles de "lectura fácil", algunos niveles utilizan dibujos o pictogramas para que la asociación de las ideas sea más sencilla, y aporta las pautas principales para elaborar un documento de este tipo: se deben emplear frases cortas, evitar el uso de frases negativas y de demasiados números (los números es mejor que se escriban con cifras en lugar de letras), no se deben emplear metáforas o comparaciones que resulten confusas, hay que intentar transmitir un mensaje en cada frase y, por supuesto, ser claro, conciso y directo.

La "lectura fácil" posibilita el acceso a documentos de naturaleza tan variada como son las noticias ${ }^{1}$ o la Constitución Europea ${ }^{2}$.

\footnotetext{
${ }^{1}$ Discapnet, "Noticias fáciles", [en línea], <http://www.noticiasfacil.es/ES/Paginas/index.aspx>. [Consulta: 08/12/2013].

2 FEAPS, "Constitución Europea Fácil", [en línea], <http://www.feaps.org/personas/ publicaciones.htm>. [Consulta: 08/12/2013].
} 


\section{3. ¿Qué es la discapacidad intelectual?}

De acuerdo con la AAMR (American Association on Mental Retardation), cuya cita queda recogida en el documento de la Confederación Española de Organizaciones a favor de las Personas con Discapacidad Intelectual (FEAPS):

La discapacidad intelectual se refiere a limitaciones sustanciales en el funcionamiento actual. Se caracteriza por un funcionamiento intelectual significativamente inferior a la media, que coexiste junto a limitaciones en dos o más de las siguientes áreas de habilidades de adaptación: comunicación, cuidado propio, vida en el hogar, habilidades sociales, uso de la comunidad, autodirección, salud y seguridad, contenidos escolares funcionales, ocio y trabajo (FEAPS: en línea).

Por otro lado, hemos de distinguir las causas que conforman los tipos de discapacidad intelectual. Entre las más frecuentes la CDC (Centers for Disease Control and Prevention) señala que dentro de los conocidos como síndromes de influencia prenatal se encuentran el síndrome de Down, el síndrome alcohólico fetal, el síndrome X frágil, los trastornos genéticos y los defectos congénitos e infecciones. Entre las que suceden durante el parto o poco después del nacimiento del bebé se encuentran las lesiones graves de la cabeza, los accidentes cerebrovasculares y ciertas infecciones (CDC: en línea).

En mi caso, he tenido la oportunidad de llevar a cabo junto con personas con síndrome de Down la propuesta práctica que voy a desarrollar en este artículo. Según Down España, el síndrome de Down es:

Una alteración genética producida por la presencia de un cromosoma extra (o una parte de él) en la pareja cromosómica 21 , de tal forma que las células de estas personas tienen 47 cromosomas con tres cromosomas en dicho par (de ahí el nombre de trisomía 21), cuando lo habitual es que sólo existan dos.

Este error congénito se produce de forma natural y espontánea, sin que exista una justificación aparente sobre la que poder actuar para impedirlo (Down España: en línea).

De acuerdo con el informe más reciente hecho público por el Estudio Colaborativo Español de Malformaciones Congénitas, durante el período 1980-2007 se diagnosticaron 11 de cada 10000 niños nacidos con síndrome de Down (Down España 2013: 24) y según los datos recogidos del último informe en 2008 en España viven aproximadamente 34000 personas con esta condición (Down España 2013: 26).

\section{Pasos previos a la elaboración de los subtítulos adaptados}

Tras los datos obtenidos, me decidí a investigar sobre una práctica traductora que permitiera la accesibilidad de contenido multimedia a personas con discapacidad intelectual. Esta investigación comienza con una entrevista a personas con síndrome de Down, en concreto, dos chicas (a partir de este punto me referiré a ellas como 
"Informante 1" e "Informante 2" para salvaguardar su anonimato). Pude ponerme en contacto con ellas gracias a una mediadora que trabajaba como voluntaria en su vivienda y que colaboraba con el Proyecto Amigo de la asociación de Down Málaga. Con anterioridad ya había elaborado el cuestionario que les iba a realizar durante la entrevista.

El procedimiento comenzó con una entrevista que consistía en preguntas en torno a los medios audiovisuales que empleaban y las dificultades que encontraban en su uso. Las conclusiones obtenidas fueron que a ambas les gustaban las películas y las series. A pesar de ello, a la Informante 1 no le gustaba ir al cine. Pude constatar que era porque no entendía mucho de lo que se trataba en la película. En su lugar prefería Internet, donde consultaba las redes sociales, el correo electrónico y también leía algunas noticias. Por otra parte, las dos chicas coincidían en que les gustaría comprender todo lo que sucede en las películas, en las noticias o en sus series favoritas, por ejemplo, sin tener que depender de las aclaraciones de otra persona.

El segundo punto del procedimiento consistió en analizar un producto audiovisual. Tras comprobar cuál era su serie favorita les propuse un fragmento de esta. Analizamos los primeros cinco minutos de uno de sus capítulos y llegamos al acuerdo de que cada vez que algún personaje dijera una frase o una palabra cuyo significado no conocieran, me preguntarían. Así, cada vez que ellas lo demandaban o yo lo creía pertinente deteníamos el vídeo y proponíamos una aclaración que iba anotando para posteriormente elaborar una propuesta accesible. Durante la visualización del vídeo no solo observé cómo se entusiasmaban cuando lo entendían, sino que además ellas me lo confirmaron.

Me gustaría añadir un tercer punto de interés: la Informante 2 tenía mayor dificultad lectora, lo que me hizo pensar que al igual que hallamos adaptaciones de contenido audiovisual conforme a diferentes grados de discapacidad, en este caso debería pensar en cómo adaptar mi propuesta para que fuese accesible a las distintas necesidades de cada persona con discapacidad intelectual. En un principio, había pensado apoyarme en los distintos tipos de TAV existentes con la idea de que sirviesen también como puente de accesibilidad entre los mensajes multimedia y las personas con discapacidad intelectual. Pensé en la AD para la Informante 2 y el subtitulado para la Informante 1. En principio no encontré ningún problema con el subtitulado, el programa utilizado fue Subtitle Workshop en su versión 2.51. Sin embargo, pude observar que la AD presentaba algunos problemas en torno al fragmento seleccionado de la serie, ya que los huecos aprovechables para insertar audiodescripciones con el contenido que les planteaba dificultad eran escasos, así que en más productos audiovisuales podría ocurrir lo mismo. Finalmente opté por el subtitulado. No obstante, quienes posean mayor dificultad a la hora de realizar una léctura ágil, en el caso de que no sea posible ayudarnos de la $\mathrm{AD}$, será necesario adaptar algunos parámetros de esta modalidad. Para ello, debemos reajustar algunas reglas de los parámetros temporales, de manera que obtengamos mayor espacio de tiempo de reproducción del subtítulo en pantalla para poder leerlo y procesarlo. 


\section{Pautas de la propuesta}

Antes de comenzar a enumerar las pautas que he seguido, me gustaría aclarar que esta propuesta, a primera vista, se basa en un tipo de subtitulado muy diferente del tradicional y solo voy a utilizarlo cuando sea conveniente, es decir, cuando espectadores con discapacidad intelectual requieran una aclaración. La gran diferencia estriba en que este subtitulado no consistirá en reproducir las mismas palabras que enuncian los actores, sino que se utilizarán explicaciones sencillas para transmitir las informaciones que sean difíciles de comprender. Las pautas que he seguido son las espaciales, temporales y de ortotipografía que recoge Díaz Cintas en su libro Teoría y práctica de la subtitulación Inglés-Español haciendo algunas adaptaciones que he creído convenientes.

A continuación me dispongo a desarrollar un comentario esquemático sobre los parámetros espaciales y temporales más significativos dentro de la práctica llevada a cabo. En ningún momento he superado la pauta generalizada de dos líneas por subtítulo, que siempre he situado en la parte inferior de la pantalla. Cuando se ha dado el caso de la existencia de un subtítulo monolineal, lo he colocado en la línea inferior de subtítulo, de forma que oculte la menor parte posible de la imagen. No he excedido los 35 caracteres por línea de subtítulo ya que Díaz Cintas (2003: 149) señala que: "Cada una de las dos líneas de un subtítulo no puede exceder de los 28 a 40 caracteres y espacios, dependiendo de los criterios de la distribuidora o estudio de subtitulado y del canal de transmisión. El número mágico suele ser 35". También debemos de tener en cuenta una longitud mínima, Díaz Cintas indica que los subtítulos no deben ser inferiores a 4 o 5 espacios y deben permanecer al menos un segundo en pantalla, lo ideal es uno y medio. Respecto al tipo de letra, en este caso he usado la MS Sans Serif puesto que se recomienda usar un tipo de letra sin serifa, y la fuente de color blanco sobre fondo oscuro.

Las adaptaciones que he hecho se producen principalmente en torno a los parámetros temporales. Podemos emplear la regla de los seis segundos aunque, en mi opinión, los subtítulos deberían de permanecer más tiempo en pantalla puesto que estas personas normalmente no tienen una gran velocidad lectora. Incluso podemos encontrar también personas con mayor dificultad de comprensión lectora como es el caso de la Informante 2. En este caso deberemos adaptar esta regla ampliando el espacio de tiempo que se mantienen los subtítulos en pantalla. La única objeción sería que nos saltaríamos una de las pautas generales, la que concierne a los tiempos de entrada y salida de los subtítulos de manera que se respete la sincronía temporal entre el momento de enunciación del texto oral y la aparición en pantalla del texto escrito. No obstante, hay que tener en cuenta que únicamente se utilizarán subtítulos cuando exista alguna frase, expresión o término que no se entienda y que requiera una explicación, por tanto, en la mayoría de los casos no habría ningún problema en "pisar" un nuevo subtítulo puesto que tendremos un margen de uno o varios minutos hasta el próximo subtítulo, ya que esta propuesta no contempla el uso continuado de subtítulos.

Al modificar los tiempos de entrada y salida de los subtítulos puede ocurrir que no se respeten algunos cambios de escena. Díaz Cintas (2003: 155) sostiene que "si 
el subtítulo se mantiene en pantalla durante un cambio de plano, el ojo del espectador cree que ha habido un cambio de subtítulo e inconscientemente comienza a leerlo de nuevo, con la consiguiente pérdida de tiempo". Sin embargo, aquí no hablamos del subtitulado destinado a un espectador con una velocidad de lectura media sino de una modalidad que se adapte a personas con discapacidad intelectual que requieren mayor tiempo para leer y procesar la información.

Para terminar con los parámetros temporales, me gustaría recordar que es necesario el uso de subtítulos diferentes para los múltiples canales debido a la variación de longitud de líneas. Por ejemplo, una línea no tendrá la misma longitud en la televisión que en el cine.

En torno a la dimensión ortotipográfica, no veo razón alguna para no seguir las pautas estandarizadas (véanse las recopiladas por Díaz Cintas en el Capítulo 6 "Dimensión ortotipográfica" de su libro Teoría y práctica de la subtitulación InglésEspañol).

A continuación, me gustaría comentar dos cuestiones fundamentales que me planteaba al elaborar los subtítulos: ¿debería realizar la traducción intralingüística en primera o en tercera persona?, ¿debería subtitular cada frase que pronuncian los actores o simplemente lo que no entienden?

En lo que respecta a la primera pregunta creo que más bien se trata de la opinión particular de cada uno, pero quizás deberíamos basarnos en que en este caso no se trata una descripción (como sería en el caso de la $\mathrm{AD}$ ), sino de la traducción de enunciados en un lenguaje más sencillo. Por lo tanto, me he decantado por el uso de la primera persona.

En torno a la segunda pregunta, con respecto a la práctica llevada a cabo, no veo la necesidad de subtitular todo el capítulo dado que podría resultar pesado para los receptores, bastaría con subtitular aquel contenido que presente dificultad de comprensión.

Para ello es necesario documentarse acudiendo al propio receptor, aunque esto no podrá realizarse para todo el material multimedia existente por razones de tiempo o económicas (transporte del traductor, necesidad inmediata de traducir un producto a punto de estrenarse, etc.). Creo que lo más conveniente sería que este campo se investigase de manera que los traductores trabajen codo con codo con personas con discapacidad intelectual y de diferentes grados. Solamente así se podrán elaborar unas pautas generales adecuadas y específicas.

En el presente estudio se puede aventurar que las dificultades principales se encuentran en las oraciones subordinadas complejas, el contenido metafórico, la ironía, los tecnicismos y los enunciados que los actores interpretan tan rápidamente que apenas se captan.

Finalmente, me gustaría adjuntar a modo de ejemplo una tabla con la transcripción del texto origen así como los enunciados de los subtítulos del texto meta, cuyas soluciones fueron aportadas de forma conjunta con ambas chicas: 


\begin{tabular}{|c|c|}
\hline En todas las familias cuecen habas. & En todas las familias pasa algo. \\
\hline $\begin{array}{l}\text { Pero lo que yo creo es que en algunas } \\
\text { cuecen más que en otras. }\end{array}$ & Algunas tienen más problemas que otras. \\
\hline [...] ha ocurrido un fenómeno. & Ha ocurrido algo sorprendente. \\
\hline $\begin{array}{l}{[\ldots] \text { que consiste en que ahora nosotros }} \\
\text { parecemos mucho más mendrugos que } \\
\text { antes. }\end{array}$ & $\begin{array}{l}\text { Ahora nosotros parecemos más tontos que } \\
\text { antes. }\end{array}$ \\
\hline $\begin{array}{l}{[\ldots] \text { cree que esto es una cuestión de }} \\
\text { genética. }\end{array}$ & Porque nos parecemos a nuestros padres. \\
\hline Lo que yo veo & Yo pienso \\
\hline es que nos dejan a la altura del betún. & que nos hacen parecer tontos. \\
\hline $\begin{array}{l}{[\ldots] \text { que no habéis "pegao" un palo al }} \\
\text { agua... }\end{array}$ & ¡No habéis hecho nada! \\
\hline $\begin{array}{l}\text { (título del capítulo de la serie) "El Atlético } \\
\text { de Santa Justa F.C." }\end{array}$ & El equipo de fútbol de su barrio \\
\hline $\begin{array}{l}\text { Si el Atlético de Santa Justa ha sido la } \\
\text { revelación del campeonato [...] }\end{array}$ & Si el equipo es el mejor del campeonato \\
\hline $\begin{array}{l}\text { ¿Qué pasa Santiago te van a dar el nobel o } \\
\text { qué? }\end{array}$ & ¿Santiago te van a dar un trofeo? \\
\hline El nobel al mejor tarugo. & Un trofeo al más tonto. \\
\hline $\begin{array}{l}\text { [...] que vuelve neandertales a los tíos de } \\
\text { domingos }\end{array}$ & $\begin{array}{l}\text { que vuelve tontos a los tíos que ven todo el } \\
\text { domingo la tele. }\end{array}$ \\
\hline $\begin{array}{l}\text { Mi tío y mi padre son los que llevan ahí } \\
\text { "to" el cotarro, y no el vejestorio ese de } \\
\text { Gervasio. }\end{array}$ & $\begin{array}{l}\text { Mi tío y mi padre son los que mandan, no } \\
\text { ese viejo. }\end{array}$ \\
\hline $\begin{array}{l}{[\ldots] \text { comparado con la felicidad de esta }} \\
\text { familia. }\end{array}$ & con que la familia esté contenta. \\
\hline En vez de dar el “coñazo” a Lucía [...] & No molestes a Lucía. \\
\hline $\begin{array}{l}\text { Eso de mendigar unas décimas es de } \\
\text { miserables. }\end{array}$ & $\begin{array}{l}\text { Pedirle que te suba medio punto es de } \\
\text { miserables. }\end{array}$ \\
\hline Un poco de dignidad chaval $[\ldots]$ & Compórtate, chaval \\
\hline $\begin{array}{l}\text { Me estoy preparando por si algún día cae la } \\
\text { lotería. }\end{array}$ & Me estoy preparando por si hay suerte. \\
\hline
\end{tabular}

Me gustaría señalar que con frecuencia se da el caso de la repetición de una misma palabra en varios subtítulos consecutivos en lugar de buscar sinónimos u otras alternativas y esto se debe a que el vocabulario de estas personas es más restringido, pero considero que esta repetición no conlleva ningún problema puesto que el fin de esta práctica es que el receptor comprenda el contenido del mensaje, y para ello se usarán repeticiones o cualquier otro procedimiento necesario para conseguir un estilo claro, conciso y directo. 


\section{Conclusiones}

Tras el trabajo realizado, fundamentado en estudios académicos previos y en mi propia formación en el ámbito de la TAV, creo estar en disposición de confirmar que no he encontrado indicios en ningún área dentro de la traducción que facilite la comprensión de los mensajes multimedia a quienes presentan discapacidad intelectual, a pesar de la demanda al respecto.

Solo algunas organizaciones y entidades como Discapnet ofrecen adaptaciones de determinados documentos de interés general para que se conviertan en documentos llamados de "lectura fácil".

En mi opinión, esta idea se podría trasvasar al terreno de la traducción, de forma que, al igual que existe el SPS o la AD, los traductores pudieran desarrollar subtítulos adaptados (o "subtítulos fáciles", por continuar con la denominación utilizada por Discapnet) que pudieran posibilitar a las personas con discapacidad intelectual la comprensión de mensajes multimedia. Si este fuera el caso, se deberían seguir unas pautas de subtitulado un tanto alejadas de las tradicionales, pero no por ello de consecución imposible, de manera que pudiéramos incluso hablar de una nueva modalidad de traducción en el terreno de la accesibilidad a los medios.

Los estudios empíricos como el presentado en este trabajo deberían ser la base sobre la que identificar necesidades para construir nuevas realidades profesionales.

\section{Referencias bibliográficas}

ASOCIDE, «Sistemas de comunicación alfabéticos», [en línea], <http://www.asocide.org/personas-sordociegas/sistemas-de-comunicacion/alfabeticos/>. [Consulta: 10/12/2013].

ASOCIDE, «Sistemas de comunicación no alfabéticos», [en línea], <http://www.asocide.org/ personas-sordociegas/sistemas-de-comunicacion/no-alfabeticos/>. [Consulta: $10 / 12 / 2013]$.

CDC, «Intellectual Disability Fact Sheet» [en línea], <http://www.cdc.gov/ncbddd/ actearly/pdf/parents_pdfs/IntellectualDisability.pdf>. [Consulta: 08/12/2013].

CENTAC, «Expertos en accesibilidad cognitiva piden que se aplique la ley para acercar las TIC a las personas con discapacidad» (2012), [en línea], <http://www.centac.es/es/content/ expertos-en-accesibilidad-cognitiva-piden-que-se-aplique-la-ley-para-acercar-las-ticlas-per>. [Consulta: 08/12/2013].

Díaz CinTAS, J., «Traducción audiovisual y accesibilidad», en: Jiménez HuRTAdo, C. (ed.), Traducción y accesibilidad. Subtitulación para sordos y audiodescripción para ciegos: nuevas modalidades de Traducción Audiovisual. Frankfurt am Main: Peter Lang 2007, 9-23.

DíAz CinTAS, J., Teoría y práctica de la subtitulación: Inglés/ Español. Barcelona: Ariel 2003.

DISCAPNET, «Lectura fácil», [en línea], <http://www.discapnet.es/Castellano/areastematicas/Accesibilidad/accesibilidadcomunicacion/LecturaF\%C3\%A1cil/Paginas/default.aspx $>$. [Consulta: 08/12/2013].

DisCAPNET, «Noticias fáciles», [en línea], <http://www.noticiasfacil.es/ES/Paginas/index.aspx>. [Consulta: 08/12/2013].

Down EspaÑA, «El síndrome de Down», [en línea], <http://www.sindromedown.net/ index.php?idMenu=6>. [Consulta: 08/12/2013]. 
DOWn ESPAÑA, «II Plan de acción para personas con síndrome de Down en España», (2013), [en línea], <http://www.sindromedown.net/adjuntos/cPublicaciones/56L_iiplande.pdf $>$. [Consulta: 08/12/2013].

ESPAÑA, «Ley 26/2011, de 1 de agosto, de adaptación normativa a la Convención Internacional sobre los Derechos de las Personas con Discapacidad», BOE, 184 (2011), 87478-87494, [en línea], <http://www.boe.es/boe/dias/2011/08/02/pdfs/BOE-A-2011-13241.pdf>. [Consulta: 08/12/2013].

ESPAÑA, «Ley 51/2003, de 2 de diciembre, de igualdad de oportunidades, no discriminación y accesibilidad universal de las personas con discapacidad», BOE, 289 (2003), 4318743195, [en línea], <http:/www.boe.es/boe/dias/2003/12/03/pdfs/A43187-43195.pdf >. [Consulta: 08/12/2013].

FEAPS, «Discapacidad Intelectual», [en línea], <http://www.asprodesa.org/portal/docs/ discapacidad intelectual.pdf $>$. [Consulta: 08/12/2013].

FGUAM, «Constitución Europea Fácil», Madrid: Gráficas ALTE S.L. 2005, [en línea], $<$ http://www.feaps.org/personas/publicaciones.htm $>$. [Consulta: 08/12/2013].

JiMÉNEZ HuRTADO, C., «Una gramática local del guión audiodescrito. Desde la semántica a la pragmática de un nuevo tipo de traducción», en: JimÉnez HurTado, C. (ed.), Traducción y accesibilidad. Subtitulación para sordos y audiodescripción para ciegos: nuevas modalidades de Traducción Audiovisual. Frankfurt: Peter Lang 2007, 55-80.

MÁRQUEZ LinARES, I., "Chuchotage para ciegos: un susurro ensayado», en: JiMÉNEZ HuRTADO, C. (ed.), Traducción y accesibilidad. Subtitulación para sordos y audiodescripción para ciegos: nuevas modalidades de Traducción Audiovisual. Frankfurt: Peter Lang 2007, 209-227.

Miller, C., "Access symbols for use with video content and information and communications technology devices», en: Díaz Cintas, J. / Orero, P. / Remael, A. (eds.), Media for All: Subtitling for the Deaf, Audio Description, and Sign Language. Amsterdam-New York: Rodopi 2007, 53-69.

ONU, «Convención sobre los derechos de las personas con discapacidad», [en línea], $<$ https://www.un.org/spanish/disabilities/default.asp?id=497>. [Consulta: 08/12/2013].

ONU, «Convención sobre los derechos de las personas con discapacidad y Protocolo facultativo», (2006), [en línea], <http://www.un.org/disabilities/documents/convention/ convoptprot-s.pdf $>$. [Consulta: 08/12/2013].

Orero, P., "A new dynamic umbrella», en: Topics in Audiovisual Translation. Amsterdam: John Benjamins 2004, 7-13.

QUEREDA HERRERA, M., «Interpretación simultánea/bilateral con apoyo táctil», en: JIMÉNEZ Hurtado, C. (ed.), Traducción y accesibilidad. Subtitulación para sordos y audiodescripción para ciegos: nuevas modalidades de Traducción Audiovisual. Frankfurt: Peter Lang 2007, 229-240. 